\title{
A nomogram for the transfer factor for carbon monoxide in the lungs
}

\author{
E. C. FLETCHER
}

The London Chest Hospital, London E2 9JX

\begin{abstract}
A nomogram was designed to facilitate determination of the total lung transfer factor for carbon monoxide from experimental data as obtained by the single breath method using a Resparameter.
\end{abstract}

A skilled person using a slide rule can calculate the total lung transfer factor for carbon monoxide (TLCo) from the experimental data in a few minutes. Less skilled people may find this method troublesome and time consuming. A nomogram (Fig. 1) was therefore designed for the estimation of the TLco by the single breath method using a Resparameter (P. K. Morgan Ltd.) (Meade et al., 1965). The nomogram is used to solve the equation:

where

$$
T L=\frac{160 V_{A}}{t} \log _{10}\left(\frac{\mathrm{CO}_{\mathrm{I}}}{\mathrm{CO}_{\mathrm{E}}} \cdot \frac{\mathrm{He}_{\mathrm{E}}}{\mathrm{He}_{\mathrm{I}}}\right) \ldots 1
$$

$\mathrm{TL}_{\mathrm{L}}=$ gas transfer for the whole lung $(\mathrm{ml} \mathrm{CO} /$ $\mathrm{min} / \mathrm{mmHg}$ )

$\mathrm{V}_{\mathrm{A}}=$ alveolar volume during breath holding (litres BTPS)

$\mathrm{t}=$ breath holding time (seconds)

$\mathrm{CO}_{\mathrm{I}}=\%$ carbon monoxide in inspired gas mixture

$\mathrm{CO}_{\mathrm{E}}=\%$ carbon monoxide in expired gas mixture

$\mathrm{He}_{\mathrm{I}}=\%$ helium in inspired gas mixture

$\mathbf{H e}_{\mathbf{E}}=\%$ helium in expired gas mixture and

$$
\mathrm{V}_{\mathrm{A}}=\left(\mathrm{V}_{\mathrm{I}}-\mathrm{V}_{\mathrm{DS}}\right) \frac{\mathrm{He}_{\mathrm{I}}}{\mathrm{He}_{\mathrm{E}}}
$$

where

$\mathrm{V}_{\mathrm{I}}=$ volume of gas mixture inspired (litres BTPS)

$\mathrm{V}_{\mathrm{DS}}=$ dead space (litres)

(the dead space (ml) may be assumed to be equal to the body weight (lb)).

The development of equation 1 has been discussed by Cotes (1968).

\section{METHOD}

The nomogram was designed so that the experimental data could be used to solve equation 1 . It seemed convenient to do this in six graphical steps.
1. The value of $\left(\frac{\mathrm{He}_{\mathrm{E}}}{\mathrm{He}_{\mathrm{I}}}\right)$ is obtained from graph 1 using the measured values of $\mathrm{He}_{\mathrm{E}}$ and $\mathrm{He}_{\mathrm{I}}$.

2. The alveolar volume $V_{A}$ is obtained from graph 2 using the value of $\left(\mathrm{V}_{\mathrm{I}}-\mathrm{V}_{\mathrm{DS}}\right)$ at BTPS and the $\left(\frac{H e_{E}}{H} \frac{e_{I}}{e_{i}}\right)$ value found on the first graph.

3. The value of $\left(\frac{160 V_{A}}{t}\right)$ is obtained from graph 3 using $t$, the measured time for breath holding, and the value for $\mathrm{V}_{\mathrm{A}}$ found on graph 2 .

4. The value of $\left(\frac{\mathrm{CO}_{\mathrm{I}}}{\mathrm{CO}_{\mathrm{E}}}\right)$ is obtained from graph 4 using the measured values of $\mathrm{CO}_{\mathrm{I}}$ and $\mathrm{CO}_{\mathrm{E}}$.

5. The value of $\left(\frac{\mathrm{CO}_{\mathrm{I}}}{\mathrm{CO}_{\mathrm{E}}} \cdot \frac{\mathrm{He}_{\mathrm{E}}}{\mathrm{He}_{\mathrm{I}}}\right)$ is derived from graph 5 using the volume already found for $\left(\frac{\mathrm{He}_{\mathrm{E}}}{\mathrm{He}_{\mathrm{I}}}\right)$ and $\left(\frac{\mathrm{CO}_{\mathrm{I}}}{\mathrm{CO}_{\mathrm{E}}}\right)$ on graphs 1 and 4 respectively.

6. Lastly, the transfer factor is found on graph 6 by using the $160 \mathrm{~V}_{\mathrm{A}}$ value found on graph 3 and the $\left(\frac{\mathrm{CO}_{\mathrm{I}}}{\mathrm{CO}_{\mathrm{E}}} \cdot \frac{\mathrm{He}_{\mathrm{E}}}{\mathrm{He}_{\mathrm{I}}}\right)$ value found on graph 4 .

The graphs are so positioned that a common axis makes it possible to move from one to the next until TL can be obtained in graph 6. Graphs 2, 5, and 6 are plotted with cartesian co-ordinates. Graphs 1,3 , and 4 are plotted as 'carpets' to give a greater spread: they could also have been plotted using cartesian co-ordinates which were found to be almost as satisfactory for the estimation of TLCO.

\section{USE OF NOMOGRAM}

The nomogram and instructions for its use are combined on one sheet (Fig. 1), 52 by $72 \mathrm{~cm}, \stackrel{\mathbb{Q}}{\mathscr{Q}}$ but a quarter size is almost as satisfactory. The data from one estimation are given in Table $I$ 


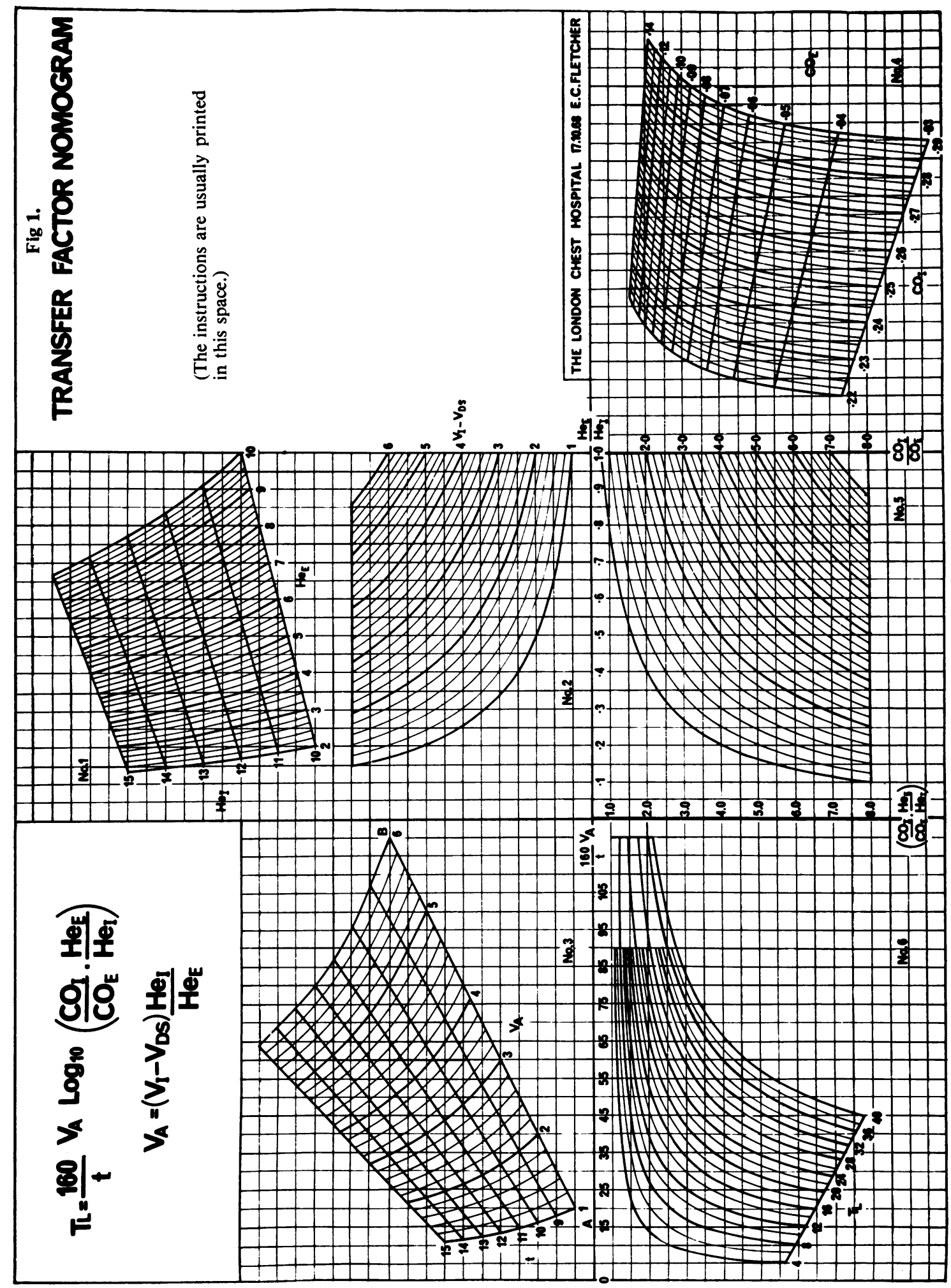

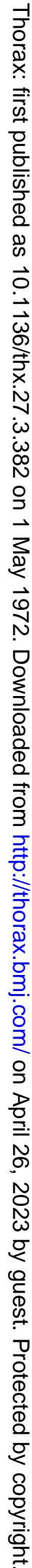


for those who wish to work an example. The results of one slide rule calculation and one nomogram procedure are given, and these are compared with a computer calculation.

T A B LE I

SPECIMEN DATA FROM ONE COMPARISON (This can be used as an exercise to test the nomogram)

\begin{tabular}{|c|}
\hline $\begin{aligned} \mathrm{He}_{1} & =13.7 \% \\
\mathrm{He}_{\mathrm{R}} & =8.35 \% \\
\mathrm{~V}_{1} & =2.750-0.140 \\
& =2.6101 \\
\mathrm{t} & =11.8 \mathrm{sec} \\
\mathrm{CO}_{1} & =0.27 \% \\
\mathrm{CO}_{\mathrm{B}} & =0.07 \%\end{aligned}$ \\
\hline $\begin{aligned} \text { Nomogram TLco } & =22 \\
\text { Calculated TLCo } & =21.81 \\
\text { Slide rule TLCo } & =21.6\end{aligned}$ \\
\hline
\end{tabular}

The nomogram is entered at graph 1 . Start with the measured values for $\mathrm{He}_{\mathrm{I}}$ and $\mathrm{He}_{\mathrm{B}}$ and enter the carpet along the $\mathrm{He}_{\mathrm{I}}$ and $\mathrm{He}_{\mathrm{E}}$ curves for their respective values. From the point of intersection of these two curves draw a vertical line through graphs 2 and 5 below. On graph 2 follow the curve for the value $\left(V_{I}-V_{D S}\right)$ until it intersects the vertical line. From this point draw a horizontal line to the left to intersect the line $A B$ on graph 3. This point gives the value of $V_{A}$ during breath holding in the test. Follow the curve for this $\mathbf{V}_{\mathbf{A}}$ value until it intersects the line for the measured value of $t$. From this point of intersection draw a vertical line down through graph 6 .

Using the measured volume of $\mathrm{CO}_{\mathrm{I}}$ and $\mathrm{CO}_{\mathrm{E}}$, enter carpet 4 along the $\mathrm{CO}_{\mathrm{I}}$ and $\mathrm{CO}_{\mathrm{E}}$ curves for their respective values. From this point of intersection of these two curves draw a horizontal line to the left to intersect with the vertical line already drawn through graph 5. From this point of intersection follow the nearest curve to the right until the $\left(\frac{\mathrm{CO}}{\bar{C} \mathrm{O}_{\mathrm{I}}}\right)$ ordinate is reached. Then draw a horizontal line to the left to intersect the vertical line already drawn in graph 6. From this point of intersection follow the direction of the nearest curve downwards until the $T_{L}$ value line is reached. This point is the value for the transfer factor.

\section{COMPARISON WITH OTHER METHODS}

Duplicate measurements for the transfer factor for carbon monoxide were made in 50 patients, and from each of these measurements the transfer factor was derived by three methods: using the nomogram, using a slide rule which included a $\log _{10}$ scale (Aristo Trilog), and calculated with a desk computer.

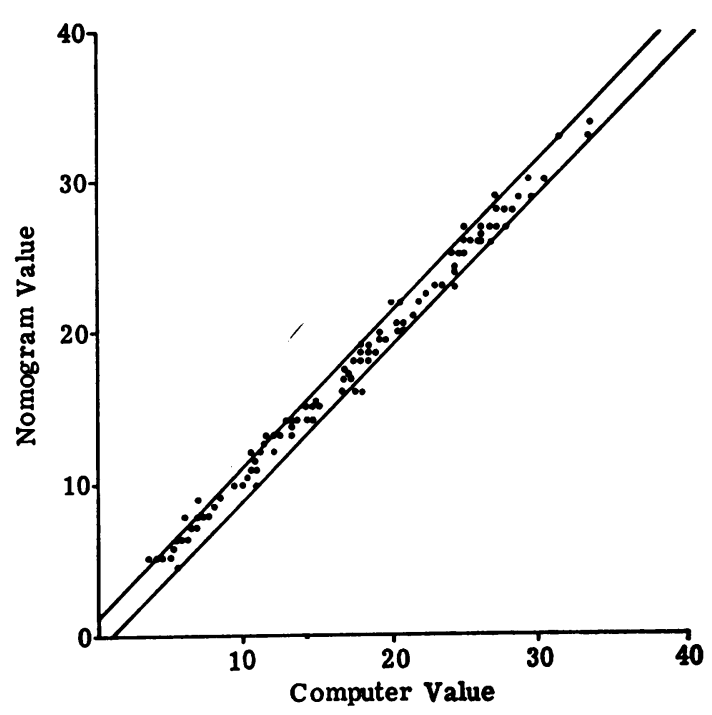

FIG. 2. A comparison between the transfer factor calculated with a computer and estimated using the nomogram. The lines represent $a$ boundary of \pm 1 unit.

All except one of the 100 nomogram estimations were within \pm 2 units of the computer calculated value (Fig. 2). For 88 of the 100 tests the nomogram estimation of the transfer factor was within \pm 1 unit of the computer calculated value (Fig. 2) and for 53 of the 100 tests the nomogram estimated value was within \pm 0.5 unit of the computer calculated value.

There was a small systematic difference between the slide rule calculation and the computer calculation: all except two of the 100 slide rule calculations were a little lower than the computer calculation. The mean difference was 0.217 unit. Ninety-three of the 100 slide rule calculations were within \pm 0.5 unit of the computer value and only one was greater than 1 unit different from the computer value.

The mean of the computer calculated values for the first of the duplicate tests was 17.67 , the mean of the nomogram estimated values was $17 \cdot 88$, and the mean of the slide rule calculated values was 17.38 (Table II). For the second of the duplicate tests the mean of the computer calculated values was 17.35 , of the nomogram estimated values was 17.61 , and the mean of the slide rule calculated values was $17 \cdot 15$ (Table III).

The mean of the numerical value of the difference between the nomogram and the computer values for the first of the duplicates was 0.538 (range 0.01-2.20) unit and for the second of the duplicates was 0.596 (range $0.00-1.91$ ) unit 然

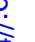


T A B L E I I

MEAN TRANSFER FACTOR DERIVED BY THE THREE METHODS FOR THE FIRST AND SECOND OF THE DUPLICATE TESTS IN 50 PATIENTS

\begin{tabular}{l|c|c}
\hline $\begin{array}{c}\text { Method of Deriving } \\
\text { Transfer Factor }\end{array}$ & $\begin{array}{c}\text { Mean Transfer Factor } \\
\text { for 50 Patients }\end{array}$ \\
\cline { 2 - 3 } & First Test & Second Test \\
\hline Computer calculation & $17 \cdot 67$ & $17 \cdot 35$ \\
Slide rule calculation & $17 \cdot 38$ & $17 \cdot 15$ \\
Nomogram estimation & $17 \cdot 88$ & $17 \cdot 61$ \\
\hline
\end{tabular}

\section{T A B L E I I I}

MEAN OF THE NUMERICAL VALUE OF THE DIFFERENCE BETWEEN TRANSFER FACTOR VALUES DERIVED BY THE THREE DIFFERENT METHODS

\begin{tabular}{|c|c|}
\hline Comparison & Mean Difference \\
\hline $\begin{array}{l}\text { Between nomogram and computer for first } \\
\text { of the duplicate tests } \\
\text { Between nomogram and computer for second } \\
\text { of the duplicate tests } \\
\text { Between slide rule and computer for first of } \\
\text { the duplicate tests } \\
\text { Between slide rule and computer for second } \\
\text { of the duplicate tests } \\
\text { Between computer value of the first and } \\
\text { second duplicate tests }\end{array}$ & $\begin{array}{c}0.538 \\
(0.01-2 \cdot 20) \\
0 \cdot 596 \\
(0.00-1 \cdot 91) \\
0 \cdot 252 \\
(0.04-1 \cdot 80) \\
0 \cdot 202 \\
(0.01-0.77) \\
1 \cdot 011 \\
(0.07-3 \cdot 15)\end{array}$ \\
\hline
\end{tabular}

(Table III). The mean of the numerical value of the difference between the computer and the slide rule calculated values for the first of the duplicates was 0.252 (range $0.04-1 \cdot 80$ ) unit and for the second 0.202 (range $0.01-0.77$ ) unit. The mean of the numerical value of the difference between the computer calculated value for the first and second of the duplicate tests was $1 \cdot 011$ (range 0.07-3.15) units.

\section{DISCUSSION}

In this article the term 'transfer factor' is used to mean the results of the estimations and calculations described. It is appreciated that physiological interpretation in subjects with airway obstruction is complex. It is also appreciated that uncertainties will arise because of a number of influences including variations in expired oxygen concentration on the helium analysers, and the effects of scrubbing of carbon dioxide and water on the expired gas volume. Such influences seem unlikely to shift the index more than one unit either way. In addition, the possibly large numerical influence of variations in haemoglobin concentration and mean capillary oxygen saturation need further study. Here we are concerned with the method as commonly used.

The differences between the duplicates of the computer calculated transfer factor values for the 50 patients indicate the range of experimental error and reproducibility of the test. The mean of the differences between the duplicates is greater than the mean of the differences between the nomogram and computer calculated values. The nomogram estimated results of the test were, therefore, within the experimental errors of the method.

The mean difference between the computer value and the slide rule value was less than the mean difference between the computer value and the nomogram value, but it was found that it was quicker to use the nomogram and it is possible that less mistakes would be made. The mean time for one slide rule calculation was 84 (range 61106) seconds. One laboratory assistant was timed unknown to her and the mean time of one nomogram estimation was 44 (range 35-57) seconds.

The nomogram was found to give a quick and reliable estimate of the transfer factor, and this could be made immediately after the test.

I wish to thank Dr. F. Prime for the computer calculations and Dr. L. H. Capel for encouragement. I should also like to thank Mr. P. K. Morgan of P. K. Morgan Ltd. (10 Manor Road, Chatham, Kent) for help with printing the nomogram and from whom copies may be obtained.

\section{REFERENCES}

Cotes, J. E. (1968). Lung Function: Assessment and Application in Medicine, 2nd ed. Blackwell Scientific Publications, Oxford.

Meade, F., Saunders, M. J., Hyett, F., Reynolds, J. A., Pearl, N., and Cotes, J. E. (1965). Automatic measurement of lung function. Lancet, 2, 573. 